\title{
Incidence and management of chylothorax after Ivor Lewis esophagectomy for cancer of the esophagus
}

\author{
Sebastian Brinkmann, MD, Wolfgang Schroeder, MD, Kristina Junggeburth, MS, \\ Christian A. Gutschow, MD, Marc Bludau, MD, Arnulf H. Hoelscher, MD, and Jessica M. Leers, MD
}

\begin{abstract}
Objective: Chylothorax is a major complication after esophagectomy. As recent studies refer to heterogeneous patient cohorts and surgical procedures, this study was conducted to report the incidence and evaluate the optimal management of chylous fistula in patients treated with transthoracic esophagectomy and 2-field lymphadenectomy for esophageal cancer.
\end{abstract}

Methods: From January 2005 to December 2013, a total of 906 patients underwent transthoracic esophageal resection for esophageal carcinoma at our institution. En bloc esophagectomy was performed with routine supradiaphragmatic ligation of the thoracic duct. The incidence of chylothorax, and associated morbidity and mortality, were analyzed, and subsequent therapeutic management was reviewed.

Results: Chylothorax after Ivor Lewis esophagectomy was observed in $17(1.9 \%)$ patients. Fifteen patients required surgical intervention with rethoracotomy and repeat duct ligation. Thoracic duct ligation was successful in all patients. Two patients died within 90 days after primary esophageal resection. The median time between initial tumor resection and rethoracotomy was 13 days. Average daily chest-tube output at time of reoperation was $1900 \mathrm{~mL}$. In 2 patients, pleural effusion did not exceed $1000 \mathrm{~mL}$ per day. In these cases, conservative management with additional thoracic drainage and total parenteral nutrition led to complete resolution of chylous fistula.

Conclusions: Occurrence of chylothorax after prophylactic thoracic duct ligation during transthoracic esophagectomy for esophageal cancer is rare. In patients with high-output chylous fistula, an early rethoracotomy with repeat ligation of the thoracic duct is safe and helps to shorten recovery time. In cases of low-volume drainage, a conservative approach is feasible. ( $\mathrm{J}$ Thorac Cardiovasc Surg 2016;151:1398-404)

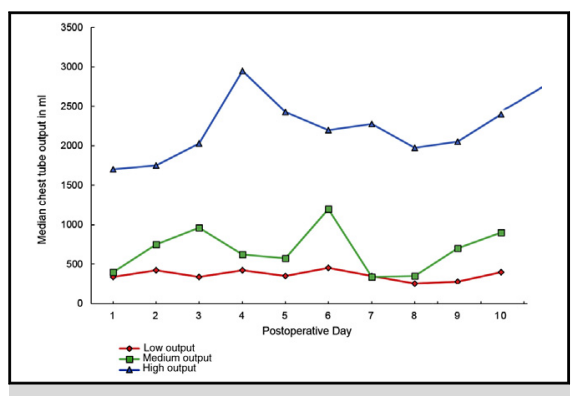

Median chest-tube output during the first 10 postoperative days, divided into 3 groups

\section{Central Message}

Routine thoracic duct ligation leads to a low rate of chylothorax; in cases of chylothorax, early repeat ligation is recommended.

\section{Perspective}

Chylothorax is rare after prophylactic thoracic duct ligation, as part of Ivor Lewis esophagectomy for esophageal cancer. With high-output chylous fistula, early rethoracotomy with repeat ligation of the thoracic duct is recommended. In cases of low-volume drainage of $<10 \mathrm{~mL} / \mathrm{kg}$ body weight, a conservative approach is feasible.

See Editorial Commentary page 1405 .
Chylothorax after transthoracic esophagectomy (TTE) for esophageal carcinoma is a rare event, with a reported ${ }^{1-3}$ incidence of $1 \%$ to $9 \%$. However, this postoperative complication is associated with considerable morbidity, particularly from pneumonia with respiratory failure. ${ }^{4}$ In addition, recent studies ${ }^{3,4}$ report mortality rates of as high as $20 \%$.

From the Department of General, Visceral and Cancer Surgery, University of Cologne, Cologne, Germany.

Received for publication May 17, 2015; revisions received Nov 29, 2015; accepted for publication Jan 17, 2016; available ahead of print Feb 28, 2016.

Address for reprints: Jessica M. Leers, MD, Department of General, Visceral and

Cancer Surgery, University of Cologne, Kerpener Str 62, 50937 Cologne, Germany

(E-mail: jessica.leers@uk-koeln.de).

$0022-5223 / \$ 36.00$

Copyright (c) 2016 by The American Association for Thoracic Surgery

http://dx.doi.org/10.1016/j.jtcvs.2016.01.030
To avoid chylothorax, several suggested approaches for thoracic duct surgery remain a topic of discussion. Although some esophageal surgeons advocate for routine supradiaphragmatic ligation of the thoracic duct, ${ }^{2,5-8}$ other experts recommend that dissection of the thoracic duct not be included as a standard procedure during TTE. ${ }^{4,9,10}$

In cases of a postoperative chylothorax, the optimal clinical management remains unclear. Therapeutic strategies include the following: conservative management, with total

Scanning this QR code will take you to the article title page. 


\section{Abbreviation and Acronym}

$\mathrm{TTE}=$ transthoracic esophagectomy

parenteral nutrition ${ }^{10,11}$ or medium-chain triglyceride diets $^{12}$; use of somatostatin and octreotide ${ }^{3,13}$; lymphangiography and percutaneous embolization of the thoracic duct $^{2,14}$; and surgical intervention with talc pleurodesis, pleurectomy, or repeat ligation of the thoracic duct. ${ }^{13} \mathrm{~A}$ review of the literature reveals that we still do not know how to determine which patients can be managed conservatively and which require surgical intervention. ${ }^{4,5,13,15}$ In this context, the timing of reoperation remains incompletely specified. ${ }^{16,17}$ This retrospective analysis summarizes the experience of a high-volume center for esophageal surgery and aims to draw conclusions on the optimal clinical management of chylothorax after TTE for cancer.

\section{METHODS \\ Patients}

From January 2005 to December 2013, a total of 936 patients underwent esophageal resection at the Department of General, Visceral and Cancer Surgery of the University of Cologne. Only patients treated with curative intention for esophageal cancer who had an en bloc TTE with intrathoracic reconstruction (an Ivor Lewis procedure) were included for further analysis. Patients who received a transhiatal or transthoracic resection with cervical reconstruction, or patients with esophagogastrectomy and colonic interposition were excluded. The retrospective study was approved by the Institutional Review Board of the University of Cologne.

\section{Operative Procedure}

The oncological staging consisted of a standardized workup, including endoscopy, endoluminal ultrasound, and computed tomography. Patients who had locally advanced carcinomas (uT3) received neoadjuvant radiochemotherapy up to $41.4 \mathrm{~Gy}$, and one of the following: 5-fluouracil and cisplatin, prior to 2011; carboplatin and paclitaxel (CROSS protocol) since 2012; or perioperative chemotherapy, according to standardized protocols (FLOT [fluorouracil, leucovorin, oxaliplatin, and docetaxel] or MAGIC [Medical Research Council adjuvant gastric infusional chemotherapy]). ${ }^{18-20}$

After laparoscopic or open gastric mobilization, a right-sided anterolateral thoracotomy was performed for en bloc esophageal resection and extended 2-field lymphadenectomy. The surgical procedure consisted of a routine prophylactic dissection of the thoracic duct, which was identified in its supradiaphragmatic anatomical position, next to the azygos vein, running parallel to the thoracic aorta. The duct, and its adjacent connective tissue, was dissected between 2 Overholt (Aesculap, Inc, Center Valley, Pa) clamps. Next, the caudal portion was closed, using a nonabsorbable suture of size 0 (Ethibond, Ethicon, Inc, Somerville, NJ). The upper thoracic duct was resected as part of the en bloc dissection. The complete technique of laparoscopic or open mobilization of the stomach and TTE with 2-field lymphadenectomy is described in detail elsewhere. ${ }^{21,22}$

\section{Postoperative Management}

Chest tubes were routinely removed when output was $<200 \mathrm{~mL}$ per day. During the postoperative course, the diagnosis of chylothorax was based on clinical observation of quantity and quality of chest drain output.
Chylothorax was diagnosed most often after the onset of oral intake, which routinely started 7 days after esophagectomy. At this time, the initial chest tubes were still in place in most cases. A high-output pleural effusion and an associated change in quality of the pleural fluid, from serous to milky yellowish, led to diagnosis. Whenever diagnosis of a chylothorax was questionable, a provocation test, with oral intake of $200 \mathrm{~mL}$ of cream, led to confirmation of diagnosis. Chest-tube output is presented ${ }^{5}$ as daily rate $(\mathrm{mL})$, and ratio of drainage to body weight $(\mathrm{mL} / \mathrm{kg}$ body weight).

In all cases, a primarily conservative approach was initiated for at least 2 days. Conservative management of thoracic duct injury consisted of total parenteral nutrition, and if necessary, an additional pleural drainage. If daily chest-tube output did not decrease, early surgical management was pursued. In these cases, the patient received $200 \mathrm{~mL}$ of cream the evening before the operation, to facilitate identification of the injured duct during rethoracotomy. Here, via a right-sided thoracotomy, pleural adhesiolysis and partial mobilization of the gastric tube was performed, to visualize the thoracic aorta in the posterior mediastinum. After identification of the leaking duct on the distal aorta, a supradiaphragmatic suture between the diaphragm and the previous ligation was performed, using another nonabsorbable suture of size 0 (Ethibond). Reoperation was finished by an extensive lavage of the pleural cavity with saline, with the chest tube in place.

\section{Data Collection}

Data for all patients were routinely documented in a database for patients who have esophageal cancer. In the study population, data collection included patient characteristics and demographics, tumor characteristics, histopathologic parameters, neoadjuvant therapy, and type of surgery. Length of hospital stay, postoperative morbidity, and in-hospital mortality were recorded, and postoperative complications were analyzed. Preoperative albumin levels were determined 1 day before esophagectomy. The reported postoperative albumin levels represented the minimum of daily measurements in the postoperative course. Daily chest-tube output was documented, and for each patient, the average output per day was calculated. In addition, we documented daily chest-tube output in 34 randomly selected patients who did not have chylothorax (ratio: 2 to 1), as performed by Shah and colleagues. ${ }^{4}$ We defined 3 groups, based on chest-tube output as a ratio of drainage volume and body weight $(\mathrm{mL} / \mathrm{kg})$ : low $=<10 ;$ medium $=10-20 ;$ and high $=>20$.

All data were collected using Excel 2013 (Microsoft Corporation, Redmond, Wash). Statistical analysis was performed using SPSS 22.0 software (SPSS, Inc, Chicago, Ill). Analyses were based on descriptive means and median. The Student $t$ test was used to describe differences between groups. To evaluate additional risk factors for postoperative chylothorax, we performed a multivariate analysis as logistic regression analysis, with backward elimination of nonsignificant factors $(P>.10)$.

\section{RESULTS}

According to the inclusion criteria, the final study population consisted of 906 patients. The study group consisted of 143 women and 670 men, with a median age of 61.9 (range: $29-92$ ) years. A total of 484 (53.4\%) patients had esophageal adenocarcinoma; $422(46.6 \%)$ had squamous cell carcinoma of the esophagus. According to clinical staging, $552(60.9 \%)$ patients with cT3/4 carcinomas received neoadjuvant radiochemotherapy or chemotherapy. Chylothorax after esophagectomy was identified in $17(1.9 \%)$ patients. The study group consisted of 4 women and 13 men, with a median age of 68.7 (range: 44-80) years. A total of $12(70.6 \%)$ patients had adenocarcinoma. Eleven $(64.7 \%)$ patients received neoadjuvant 
TABLE 1. Demographics and characteristics of 17 patients who had chylothorax after transthoracic esophagectomy and routine thoracic duct ligation

\begin{tabular}{lc}
\hline \multicolumn{1}{c}{ Preoperative characteristics } & n $(\%)$ or median (IQR) \\
\hline Gender, male & $13(76.5)$ \\
Age $(\mathrm{y})$ & $68.7(44-80)$ \\
BMI $\left(\mathrm{kg} / \mathrm{m}^{2}\right)$ & $22.4(18-34)$ \\
$<18.5-<15$ & $1(5.9)$ \\
$>18.5-<25$ & $12(70.6)$ \\
$>25$ & $4(23.5)$ \\
ASA category & \\
1 & $1(5.9)$ \\
2 & $11(64.7)$ \\
3 & $4(23.5)$ \\
4 & $1(5.9)$ \\
History of tobacco use & $10(58.8)$ \\
Active smoker & $7(41.2)$ \\
Neoadjuvant radiochemotherapy & $11(64.7)$ \\
Tumor-specific variables & \\
Histology & \\
Squamous cell carcinoma & \\
Adenocarcinoma & $5(29.4)$ \\
Locally advanced tumors ([y]pT3/T4) & $12(70.6)$ \\
Number of lymph nodes removed & $7(41.2)$ \\
Lymph node metastasis & $27(9-41)$ \\
Location & $8(47.1)$ \\
Middle third & \\
Lower third & $10(58.8)$ \\
\hline & $7(41.2)$ \\
\hline I &
\end{tabular}

$I Q R$, Interquartile range; $B M I$, body mass index; $A S A$, American Society of Anesthesiologists; y, patient with neoadjuvant therapy.

radiochemotherapy. All tumors were located in the middle $(n=7)$ or lower $(n=10)$ third of the esophagus. Tumor-free margins of resection were achieved in all patients. Further details regarding patients and tumor

TABLE 2. Comorbidities and complications in 17 patients who had chylothorax

\begin{tabular}{lc}
\hline Comorbidities and complications & n (\%) or mean (range) \\
\hline Comorbid conditions & $12(70.6)$ \\
COPD/Asthma & $6(35.3)$ \\
Previous pulmonary embolism & $2(11.8)$ \\
Previous chest surgery & $1(5.9)$ \\
Arterial hypertension & $9(52.9)$ \\
Diabetes & $1(5.9)$ \\
Serum albumin status (g/L), mean (range) & \\
Preoperative & $38(34-47)$ \\
Postoperative & $22.0(16.3-31.2)$ \\
Loss & $15.3(6.8-25.8)$ \\
Major postoperative complications & $10(58.8)$ \\
Respiratory failure & $7(41.2)$ \\
Tracheotomy & $3(17.6)$ \\
Acute kidney failure* & $5(29.4)$ \\
Sepsis & $5(29.4)$ \\
\hline
\end{tabular}

COPD, Chronic obstructive pulmonary disease. *According to the Acute Kidney Injury Work Group (2012) clinical practice guideline. ${ }^{23}$

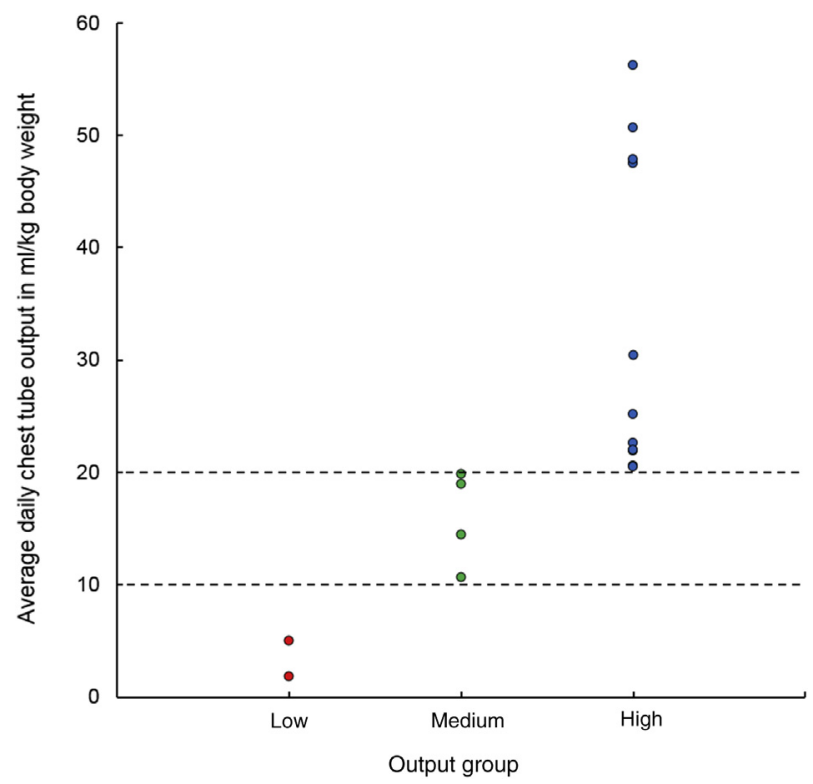

FIGURE 1. Average daily chest-tube output in relation to body weight in 17 patients with chylothorax. Three groups are defined by daily output: low, medium, and high.

characteristics are shown in Table 1, and data on comorbidities and postoperative complications in Table 2.

Chest-tube output of $>1000 \mathrm{~mL}$ per day led to the diagnosis of chylothorax in all but one case, in which chest-tube output was $<1000 \mathrm{~mL}$, but noticeably yellowish. A provocation test with cream confirmed the diagnosis in 8 patients. Chest-tube output as a ratio of drainage volume and body weight $(\mathrm{mL} / \mathrm{kg}$ ) was used to define 3 groups of patients in our study population (Figure 1). In both patients who had a ratio of $<10 \mathrm{~mL} / \mathrm{kg}$ (low-output group), conservative treatment was successful. The time interval between placement and removal of the initial pleural chest tube was 4 and 17 days, respectively. Neither patient had other major complications during their hospital stay. Postoperative hospital stay was increased to 26 and 34 days, respectively. The median chest-tube output during the first 10 postoperative days, for all 17 patients, was divided into 3 groups (low, medium, and high) (Figure 2).

A comparison of the 24-hour chest-tube output of patients with versus without chylothorax, on each of the first 10 days after primary resection, showed that the median daily chest-tube output was significantly higher in patients who had the latter diagnosis of chylothorax, compared with the control group (1738 vs $325 \mathrm{~mL}$ per day; $P<.01)$ (Figure 3). A total of $4(23.5 \%)$ patients had chest-tube output between 10 and $20 \mathrm{~mL} / \mathrm{kg}$ (medium-output group). In these patients, the initial postoperative course was uneventful, and the chest tube was routinely removed with low output. Because of pleural effusion on radiograph, a second chest tube was placed, and the fluid was suspicious for chyle. The time from esophagectomy to repeat thoracic 


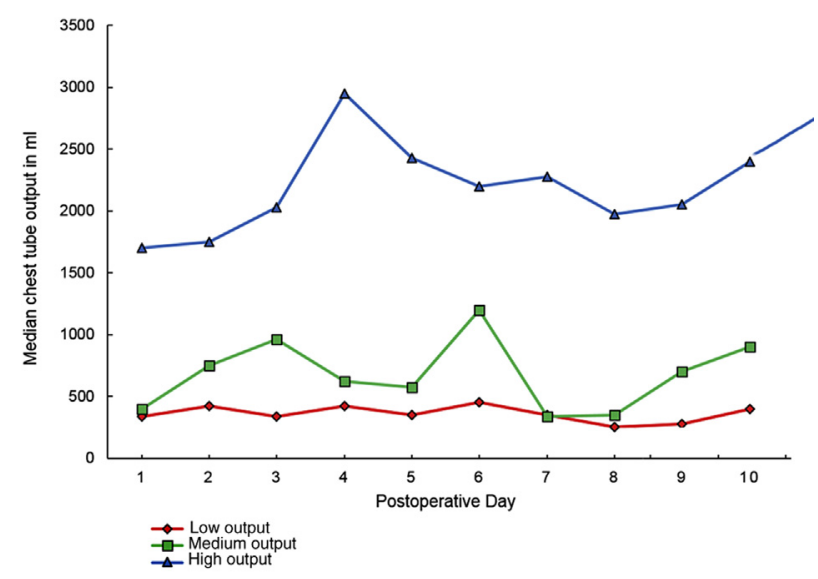

FIGURE 2. Median chest-tube output during the first 10 postoperative days for all 17 patients, divided into 3 groups by daily output: low, medium, and high.

duct ligation was prolonged (29 days; range: 13-45), compared with the time (13 days; range: 4-23) for the 11 patients of the high-output group (pleural effusion $>20 \mathrm{~mL} / \mathrm{kg}$ ).

Repeat ligation of the thoracic duct was successful in 14 $(93.3 \%)$ patients. A single patient required another transthoracic duct ligation 53 days after initial esophagectomy and 18 days after rethoracotomy (Table 3 ). Three (17.6\%) patients developed an anastomotic leakage, which was diagnosed before chylothorax in all cases, and none of them developed further major complications during their postoperative course.

None of the patients died within the first 30 days. Two patients died within 90 days, giving an in-hospital mortality of $11.8 \%$. One patient died from sepsis related to a fulminant Klebsiella pneumonia infection 39 days after

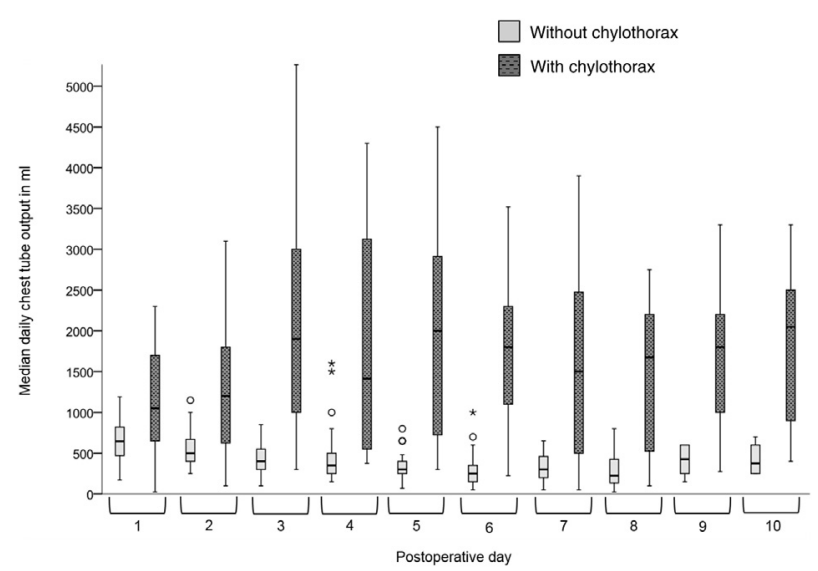

FIGURE 3. Comparison of median daily chest-tube output in patients with chylothorax $(n=17)$ and randomly selected patients without chylothorax $(\mathrm{n}=34)$. Median daily chest-tube output was significantly higher in patients with chylothorax, compared with control group (1738 vs $325 \mathrm{~mL}$ per day, $P<.01$ ). repeat thoracic duct ligation. The second patient developed sepsis of unknown origin that rapidly led to multiorgan failure 19 days after operative treatment for chylothorax.

\section{Statistical Analysis}

In the multivariate analysis, no significant risk factors were identified for chylothorax. This analysis included the variables gender, age, histology, location of tumor, T-category, N-category, and year of operation.

\section{DISCUSSION}

The present study showed a $1.9 \%$ incidence of chylothorax after Ivor Lewis esophagectomy. This percentage is at the lower limit of the incidence of $1 \%$ to $9 \%$ found in other studies ${ }^{2,5,24}$ (Table 4 ). In our opinion, the low incidence of chylothorax in our study is due to the routine supradiaphragmatic ligation of the thoracic duct.

However, the question has not been resolved of whether routine dissection of the thoracic duct is a necessary component of en bloc resection and lymphadenectomy, to improve the oncological prognosis. In a large multicenter trial, not only the nodal status but also the number of lymph nodes removed were demonstrated to be independent factors in survival. ${ }^{29}$ In addition, the threshold value for the number of lymph nodes to be removed is easier to achieve when the esophagectomy is performed as an en bloc procedure. ${ }^{29,30}$ Given that preservation of the thoracic duct is technically challenging with an en bloc esophagectomy, many esophageal surgeons recommend that the extension of dissection including the thoracic duct, for oncological reasons. This surgical approach is supported by a morphological study that showed resection of the azygos vein, as part of the en bloc esophagectomy, increased the number of resected lymph nodes. ${ }^{30}$ Furthermore, the richness of collateral lymphatic pathways seems to justify thoracic duct ligation, as it can be performed without any serious side effects. ${ }^{6,31}$

A second question concerning surgical technique is whether the incidence of chylothorax and therefore postoperative morbidity is decreased by routine dissection of the thoracic duct. Hou and colleagues ${ }^{32}$ reported an unfavorable overall survival in patients who underwent esophagectomy, mainly via left-sided thoracotomy including routine duct ligation. Furthermore, their retrospective study presented a wide variety of surgical approaches and a noticeably low rate of neoadjuvant therapy. With only $2 \%$ of Ivor Lewis esophagectomies, a side-to-side comparison to our data is difficult, as we focused strictly on this right-sided approach. A recent randomized controlled study of 653 patients undergoing right-sided TTE, treated with either routine $(\mathrm{n}=325)$ or no $(\mathrm{n}=328)$ thoracic duct ligation, showed a minimized risk of postoperative chylothorax in patients who had routine dissection and ligation of the thoracic duct during 
TABLE 3. Postoperative variables of study population, stratified by group according to chest-tube output ratio

\begin{tabular}{|c|c|c|c|}
\hline \multirow[b]{2}{*}{ Variable } & \multicolumn{3}{|c|}{ Output } \\
\hline & $\begin{array}{c}\text { Low } \\
(n=2)\end{array}$ & $\begin{array}{c}\text { Medium } \\
(n=4)\end{array}$ & $\begin{array}{c}\text { High } \\
(\mathbf{n}=\mathbf{1 1})\end{array}$ \\
\hline \multicolumn{4}{|l|}{ Time from esophagectomy (d) } \\
\hline To diagnosis & $18(9-27)$ & - & - \\
\hline To repeat duct ligation & - & $29(13-45)$ & $13(4-23)$ \\
\hline To start of oral intake & $7.5(7-8)$ & $7.5(7-8)$ & $7(6-13)$ \\
\hline \multicolumn{4}{|l|}{ Original chest tube } \\
\hline In place at repeat duct ligation & - & 0 & $11(100)$ \\
\hline Duration (d) & $10.5(4-17)$ & $11(4-25)$ & $13(4-23)$ \\
\hline \multicolumn{4}{|l|}{ Chest-tube output, median (IQR) } \\
\hline Average (mL/d) & $358(225-490)$ & $1019(578-1390)$ & $1827(1453-3144)$ \\
\hline Average (mL/kg body weight) & $3.5(1.9-5.1)$ & $16.7(10.7-19.9)$ & $25.1(20.5-56.2)$ \\
\hline Provocation test with oral intake of $200 \mathrm{~mL}$ cream & 0 & $1(25)$ & $7(64)$ \\
\hline Major complications & 0 & $3(75)$ & $7(64)$ \\
\hline Respiratory failure and pneumonia & 0 & 2 & 5 \\
\hline Tracheotomy & 0 & 1 & 2 \\
\hline Acute kidney failure* & 0 & 1 & 4 \\
\hline Anastomotic leakage & 0 & 1 & 2 \\
\hline Necrosis of gastric pull-up & 0 & 1 & 0 \\
\hline \multicolumn{4}{|l|}{ Length of stay (d) } \\
\hline Hospital & $30(26-34)$ & $44(25-90)$ & $47(29-91)$ \\
\hline ICU & $4.5(2-7)$ & $5(2-57)$ & $7(1-64)$ \\
\hline In-hospital mortality & 0 & 0 & $2(18.2)$ \\
\hline
\end{tabular}

TTE for cancer. In another study, ${ }^{2}$ the incidence of chylothorax in patients who received thoracic duct mass ligation during esophagectomy was $1.2 \%$, compared with $2.1 \%$ of patients who had preservation of the thoracic duct. Other studies $^{1,5}$ with a routine thoracic duct ligation report comparable low rates of postoperative chylothorax, of $2.1 \%$ and $2.7 \%$. In contrast to these techniques, the Pittsburgh center for esophageal surgery does not support the routine dissection and ligation of the thoracic duct.
The reported rate of chylothorax in their series ${ }^{4}$ of 862 esophagectomies is $3.8 \%$, which is 2 -fold higher than that in our series.

However, chylothorax is a serious complication, associated with substantial morbidity. As the thoracic duct drains approximately $75 \%$ of the body's lymph, ${ }^{33}$ thoracic duct injury leads to a particular type of fluid loss that can result in hypovolaemia and respiratory failure. ${ }^{13}$ In our cohort, 7 of $17(41 \%)$ patients developed pneumonia or respiratory

TABLE 4. Literature review of incidence and outcome of postesophagectomy chylothorax

\begin{tabular}{|c|c|c|c|c|c|c|c|}
\hline $\begin{array}{c}\text { First author } \\
\text { (reference) }\end{array}$ & Year & $\mathbf{n}$ & $\begin{array}{c}\text { Approach to } \\
\text { esophagectomy }\end{array}$ & $\begin{array}{l}\text { Routine ligation } \\
\text { of thoracic duct }\end{array}$ & Chylothorax & $\begin{array}{c}\text { Operative treatment } \\
\text { of chylothorax }\end{array}$ & Mortality \\
\hline Bolger (24) & 1991 & 537 & TTE and TH & Not performed & 2.0 & 27 & 45.4 \\
\hline Cerfolio (25) & 1996 & 931 & NA & NA & 2.9 & 89 & 3.7 \\
\hline Dugue (5) & 1998 & 850 & TTE & $100 \%$ & 2.7 & 39 & 8.7 \\
\hline Alexiou (11) & 1998 & 523 & TTE and TH & Not performed & 4.0 & 19 & 23.8 \\
\hline Orringer (26) & 1999 & 1085 & $\mathrm{TH}$ & NA & 1.7 & 100 & 0.0 \\
\hline Merigliano (10) & 2000 & 1787 & TTE and TH & $6 \%$ & 1.1 & 79 & 5.3 \\
\hline Hulscher (27) & 2002 & 220 & TTE and TH & $52 \%$ & 5.9 & NA & NA \\
\hline Rao (9) & 2004 & 552 & TT and TH & NA & 2.5 & 50 & 28.5 \\
\hline Lai (2) & 2011 & 653 & TTE & $50 \%$ & 1.2 & 50 & 25.0 \\
\hline Shah (4) & 2012 & 892 & TTE and TH & Not performed & 3.8 & 62 & 24.0 \\
\hline Mishra (3) & 2012 & 104 & TTE and TH & Not performed & 8.6 & 100 & 22.2 \\
\hline Kranzfelder (28) & 2013 & 1856 & TTE and TH & NA & 2.1 & 64 & 12.8 \\
\hline Present study & 2015 & 906 & TTE & 100 & 1.9 & 88 & 11.8 \\
\hline
\end{tabular}

Values are \%, unless otherwise indicated. TTE, Transthoracic esophagectomy; $T H$, transhiatal esophagetomy; $N A$, not applicable. 
failure with reintubation. These events occurred before rethoracotomy performed as a necessary treatment for chylothorax. The findings are consistent with those of another study that reported a similar rate of complications due to postesophagectomy chylothorax. ${ }^{4}$ In addition, anastomotic leakages were diagnosed before the diagnosis of chylothorax in all cases. Hypovolaemia with a continuous loss of fat-soluble vitamins, proteins, and electrolytes causes malnutrition. The resulting T-cell depletion and loss of immunoglobulins lead to significant impairment of cell-mediated immunity and humoral responses. As a consequence, patients are at higher risk for septicemia, $2,13,34$ with an incidence of sepsis ${ }^{4}$ as high as $24 \%$, comparable to that in our study.

Finally, the optimal management of postoperative chylothorax is challenging. Conservative treatment is worth the attempt, but the question of what is optimal timing for surgical intervention needs to be addressed. As mortality rates as high as $82 \%$ are reported with conservative therapeutic treatment, the time required to successfully manage chylothorax is critical. ${ }^{16}$ Several authors ${ }^{10,17,35}$ have suggested the approach of performing early reoperation, with ligation of the thoracic duct to reduce the morbidity and mortality caused by chylous fistula. Some authors ${ }^{25,28}$ recommend ligation of the thoracic duct when the amount of chylous drainage exceeds $1000 \mathrm{~mL}$ for $>7$ days.

Measures other than volume alone are needed, but are currently unreliable. Gibbons and Ahmed ${ }^{36}$ pointed out, and Maldonado confirmed, ${ }^{37}$ that the traditionally used triglyceride levels may be unreliable with patients who are fasting, especially in the postoperative setting. Merrigan and colleagues ${ }^{17}$ suggested reoperation in patients in whom chylous loss persists for $>5$ days, and the chylous leak produces $\geq 1000 \mathrm{~mL}$ per day. Other studies noted that the appearance of fluid and volume of chest-drain output alone lack sensitivity and specificity for detection of chylous leakage, and they occasionally integrated physical and biochemical analysis of chyle into their management of diagnosis. $^{2,36}$

Until the findings of this study, we used $200 \mathrm{~mL}$ of chesttube output as the cutoff to remove the chest tube, and we did not take body weight into account. When we retrospectively evaluated our data, we found that patients' chest-tube output per kg body weight correlated well with clinical outcome and necessary treatment. Three groups of patients became obvious: high; medium; and low output. In our experience, the vast majority of cases require surgery with repeat duct ligation. Yet, conservative treatment was successful in some cases. Our results indicate that the threshold for the necessity of surgery is a daily chest-tube output of $>10 \mathrm{~mL}$ per kg body weight. In an earlier series of 23 patients, Dugue and colleagues ${ }^{5}$ advocated the same cutoff of $10 \mathrm{~mL} / \mathrm{kg}$ daily of chest-tube output as an indicator for repeat thoracic duct ligation.
In contrast, 11 patients had a daily chylous output of $>20 \mathrm{~mL} / \mathrm{kg}$. In these patients, extensive chylous output led to early surgical treatment after a median of 13 days postesophagectomy. The initial chest tube was still in place at the time of repeat thoracic duct ligation in this group of patients.

A third group of patients need to be addressed separately-those in whom the initial chest tube was already removed at the time of chylothorax diagnosis and subsequent reoperation. In these cases, the average level of daily pleural drainage output to body weight was 10 to $20 \mathrm{~mL} / \mathrm{kg}$. Possibly, the initial chest-tube drainage was removed too early for these patients because the diagnosis of chylothorax was not suspected. The removal likely would have led to failed initial conservative management and a prolonged time until surgical treatment was initiated. According to the critical level of $>10 \mathrm{~mL}$ chylous output per $\mathrm{kg}$ body weight, these patients would have benefited more from an aggressive treatment of chylothorax, with early repeat duct ligation, than from an initial conservative therapeutic attempt.

\section{Limitations and Strengths}

This retrospective study of a large esophagectomy series has both strengths and limitations. We present a well defined patient cohort: All patients underwent a standardized Ivor Lewis esophagectomy for esophageal cancer, with routine duct ligation. Moreover, in all cases of chylothorax, surgical therapy was performed via the transthoracic route. Other studies often use patient cohorts that are heterogeneous in regard to primary diagnosis with various benign and malignant diseases ${ }^{4,9}$ and type of surgery with transthoracic or transabdominal resection of the esophagus. ${ }^{2-4,9}$ In addition, in cases of chylothorax, surgical therapy has been performed via both the transthoracic and transabdominal route. ${ }^{3,8}$ A limitation of this study is the low number of chylothorax cases, which makes extensive statistical analyses difficult, along with drawing evidence-based recommendation for general clinical management.

\section{CONCLUSIONS}

Given its oncological benefit in esophageal cancer patients, we recommend transthoracic en bloc esophagectomy with routine thoracic duct ligation. With this approach, the incidence of chylothorax is considerably lower, at $1.9 \%$. An average chest-tube output of $>10 \mathrm{~mL} / \mathrm{kg}$ of body weight within the first postoperative days should be the trigger for reoperation. A conservative strategy can be successful for only a low percentage of cases.

\section{Conflict of Interest Statement}

Authors have nothing to disclose with regard to commercial support. 


\section{References}

1. Dougenis D, Walker WS, Cameron EW, Walbaum PR. Management of chylothorax complicating extensive esophageal resection. Surg Gynecol Obstet. 1992;174:501-6.

2. Lai FC, Chen L, Tu YR, Lin M, Li X. Prevention of chylothorax complicating extensive esophageal resection by mass ligation of thoracic duct: a random control study. Ann Thorac Surg. 2011;91:1770-4.

3. Mishra PK, Saluja SS, Ramaswamy D, Bains SS, Haque PD. Thoracic duct injury following esophagectomy in carcinoma of the esophagus: ligation by the abdominal approach. World J Surg. 2013;37:141-6.

4. Shah RD, Luketich JD, Schuchert MJ, Christie NA, Pennathur A, Landreneau RJ, et al. Postesophagectomy chylothorax: incidence, risk factors, and outcomes. Ann Thorac Surg. 2012;93:897-904.

5. Dugue L, Sauvanet A, Farges O, Goharin A, Le Mee J, Belghiti J. Output of chyle as an indicator of treatment for chylothorax complicating oesophagectomy. $\mathrm{Br} \mathrm{J}$ Surg. 1998;85:1147-9.

6. Guo W, Zhao Y-P, Jiang Y-G, Niu H-J, Liu X-H, Ma Z, et al. Prevention of postoperative chylothorax with thoracic duct ligation during video-assisted thoracoscopic esophagectomy for cancer. Surg Endosc. 2012;26:1332-6.

7. Cagol M, Ruol A, Castoro C, Alfieri R, Michieletto S, Ancona E. Prophylactic thoracic duct mass ligation prevents chylothorax after TTE for cancer. World $J$ Surg. 2009;33:1684-6.

8. Hoeppner J, Hopt UT. Transabdominal mass ligation of the thoracic duct for the prevention of chylothorax following en bloc oesophagectomy. Eur J Cardiothoracic Surg. 2013;44:1134-6.

9. Rao DVLN, Chava SP, Sahni P, Chattopadhyay TK. Thoracic duct injury during esophagectomy: 20 years' experience at a tertiary care center in a developing country. Dis Esoph. 2004; 17:141-5.

10. Merigliano S, Molena D, Ruol A, Zaninotto G, Cagol M, Scappin S, et al. Chylothorax complicating esophagectomy for cancer: a plea for early thoracic duct ligation. J Thorac Cardiovasc Surg. 2000;119:453-7.

11. Alexiou C, Watson M, Beggs D, Salama FD, Morgan WE. Chylothorax following oesophagogastrectomy for malignant disease. Eur J Cardio-thoracic Surg. 1998; 14:460-6.

12. Mery CM, Moffett BS, Khan MS, Zhang W, Guzmán-Pruneda FA, Fraser CD, et al. Incidence and treatment of chylothorax after cardiac surgery in children: analysis of a large multi-institution database. J Thorac Cardiovasc Surg. 2014; 147:678-86.e1; discussion 685-6.

13. Nair SK, Petko M, Hayward MP. Aetiology and management of chylothorax in adults. Eur J Cardio-thoracic Surg. 2007;32:362-9.

14. Itkin M, Kucharczuk JC, Kwak A, Trerotola SO, Kaiser LR. Nonoperative thoracic duct embolization for traumatic thoracic duct leak: experience in 109 patients. J Thorac Cardiovasc Surg. 2010;139:584-90.

15. Kelly RF, Shumway SJ. Conservative management of postoperative chylothorax using somatostatin. Ann Thorac Surg. 2000;69:1944-5.

16. Wemyss-Holden SA, Launois B, Maddern GJ. Management of thoracic duct injuries after oesophagectomy. Br J Surg. 2001;88:1442-8.

17. Merrigan BA, Winter DC, O'Sullivan GC. Chylothorax. Br J Surg. 1997;84: $15-20$.

18. Al-Batran SE, Hartmann JT, Hofheinz R, Homann N, Rethwisch V, Probst S, et al. Biweekly fluorouracil, leucovorin, oxaliplatin, and docetaxel (FLOT) for patients with metastatic adenocarcinoma of the stomach or esophagogastric junction: a phase II trial of the Arbeitsgemeinschaft Internistische Onkologie. Ann Oncol. 2008;19:1882-7.

19. Cunningham D, Allum WH, Stenning SP, Thompson JN, Van de Velde CJH, Nicolson M, et al. Perioperative chemotherapy versus surgery alone for resectable gastroesophageal cancer. $N$ Engl J Med. 2006;355:11-20.
20. Van Hagen P, Hulshof MCCM, van Lanschot JJB, Steyerberg EW, Henegouwen MIVB, Wijnhoven BPL, et al. Preoperative chemoradiotherapy for esophageal or junctional cancer. N Engl J Med. 2012;366:2074-84.

21. Hölscher AH, Schneider PM, Gutschow C, Schröder W. Laparoscopic ischemic conditioning of the stomach for esophageal replacement. Ann Surg. 2007;245: 241-6.

22. Schröder W, Höscher AH, Bludau M, Vallböhmer D, Bollschweiler E, Gutschow C. Ivor-Lewis esophagectomy with and without laparoscopic conditioning of the gastric conduit. World J Surg. 2010;34:738-43.

23. Kellum JA, Lameire N, Aspelin P, Barsoum RS, Burdmann EA, Goldstein SL, et al. KDIGO Clinical practice guideline for acute kidney injury. Kidney Int Suppl. 2012;2:1-138.

24. Bolger C, Walsh TN, Tanner WA, Keeling P, Hennessy TP. Chylothorax after oesophagectomy. Br J Surg. 1991;78:587-8.

25. Cerfolio RJ, Allen MS, Deschamps C, Trastek VF, Pairolero PC. Postoperative chylothorax. J Thorac Cardiovasc Surg. 1996;112:1361-5; discussion 1365-6.

26. Orringer MB, Marshall B, Iannettoni MD. Transhiatal esophagectomy: clinical experience and refinements. Ann Surg. 1999;230:392-400; discussion 400-3.

27. Hulscher JB, van Sandick JW, de Boer AG, Wijnhoven BP, Tijssen JG, Fockens $\mathrm{P}$, et al. Extended transthoracic resection compared with limited transhiatal resection for adenocarcinoma of the esophagus. $N$ Engl J Med. 2002;347:1662-9.

28. Kranzfelder M, Gertler R, Hapfelmeier A, Friess H, Feith M. Chylothorax after esophagectomy for cancer: impact of the surgical approach and neoadjuvant treatment: systematic review and institutional analysis. Surg Endosc. 2013;27: 3530-8.

29. Peyre CG, Hagen JA, DeMeester SR, Altorki NK, Ancona E, Griffin SM, et al. The number of lymph nodes removed predicts survival in esophageal cancer: an international study on the impact of extent of surgical resection. Ann Surg 2008;248:549-56.

30. Schröder W, Vallböhmer D, Bludau M, Banczyk A, Gutschow C, Hölscher AH. The resection of the azygos vein-necessary or redundant extension of transthoracic esophagectomy? J Gastrointest Surg. 2008;12:1163-7.

31. Wurnig PN, Hollaus PH, Ohtsuka T, Flege JB, Wolf RK. Thoracoscopic direct clipping of the thoracic duct for chylopericardium and chylothorax. Ann Thorac Surg. 2000;70:1662-5.

32. Hou X, Fu J-H, Wang X, Zhang L-J, Liu Q-W, Luo K-J, et al. Prophylactic thoracic duct ligation has unfavorable impact on overall survival in patients with resectable oesophageal cancer. Eur J Surg Oncol. 2014;40: 1756-62.

33. Phang KL, Bowman M, Phillips A, Windsor J. Review of thoracic duct anatomical variations and clinical implications. Clin Anat. 2014;27:637-44.

34. Orange JS, Geha RS, Bonilla FA. Acute chylothorax in children: selective retention of memory T cells and natural killer cells. J Pediatr. 2003; 143:243-9.

35. Buchan KG, Hosseinpour AR, Ritchie AJ. Thoracoscopic thoracic duct ligation for traumatic chylothorax. Ann Thorac Surg. 2001;72:1366-7.

36. Gibbons SM, Ahmed F. Chylothorax diagnosis: Can the clinical chemistry laboratory do more? Ann Clin Biochem. 2014;52:173-6.

37. Maldonado F, Hawkins FJ, Daniels CE, Doerr CH, Decker PA, Ryu JH. Pleural fluid characteristics of chylothorax. Mayo Clin Proc. 2009;84:129-33.

Key Words: chylothorax, thoracic duct ligation, transthoracic esophagectomy, chest tube, Ivor Lewis 